\title{
Role of liraglutide in Alzheimer's disease pathology
}

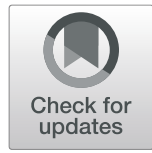

Maria Vargas-Soria ${ }^{1 \dagger}$, Maria Jose Carranza-Naval ${ }^{1,2+}$, Angel del Marco ${ }^{1 *}$ and Monica Garcia-Alloza ${ }^{1 *}$ (D)

\begin{abstract}
Background: The described relationship between Alzheimer's disease (AD) and type 2 diabetes (T2D) and the fact that $A D$ has no succesful treatment has led to the study of antidiabetic drugs that may limit or slow down $A D$ pathology.

Main body: Although T2D treatment has evident limitations, options are increasing including glucagon-like peptide 1 analogs. Among these, liraglutide (LRGT) is commonly used by T2D patients to improve $\beta$ cell function and suppress glucagon to restore normoglycaemia. Interestingly, LRGT also counterbalances altered brain metabolism and has anti-inflammatory properties. Previous studies have reported its capacity to reduce AD pathology, including amyloid production and deposition, tau hyperphosphorylation, or neuronal and synaptic loss in animal models of $A D$, accompanied by cognitive improvement. Given the beneficial effects of LRGT at central level, studies in patients have been carried out, showing modest beneficial effects. At present, the ELAD trial (Evaluating Liraglutide in Alzheimer's Disease NCT01843075) is an ongoing phase llb study in patients with mild AD. In this minireview, we resume the outcomes of LRGT treatment in preclinical models of $A D$ as well as the available results in patients up to date.
\end{abstract}

Conclusion: The effects of LRGT on animal models show significant benefits in AD pathology and cognitive impairment. While studies in patients are limited, ongoing clinical trials will probably provide more definitive conclusions on the role of LRGT in AD patients.

Keywords: Liraglutide, Alzheimer's disease, Amyloid, Tau, Inflammation, Cognition

\section{Background}

Alzheimer's disease (AD) is the most common cause of dementia. Type 2 diabetes (T2D) may increase the risk to suffer AD over two-fold [1, 2]. However, it remains unclear whether T2D and AD are parallel phenomena or synergistic diseases linked by vicious pathological cycles [3]. In this sense, findings in patients relating T2D to AD classical pathology are inconsistent [4]. However, T2D increases the risk to develop $A D$, even after

\footnotetext{
* Correspondence: angeljose.delmarco@uca.es; monica.garcia@uca.es

${ }^{\dagger}$ Maria Vargas-Soria and Maria Jose Carranza-Naval contributed equally to this work.

${ }^{1}$ Division of Physiology, School of Medicine, Instituto de Investigacion Biomedica de Cadiz (INIBICA), Universidad de Cadiz, Edificio Andres Segovia, C/Dr. Maranon 3, 3er piso, Cadiz, Spain

Full list of author information is available at the end of the article
}

adjusting for vascular risk factors $[5,6]$ and if only $10 \%$ of diabetic patients end up suffering $\mathrm{AD}$, the number of $\mathrm{AD}$ patients will double [2]. This situation and the fact that AD has no successful treatment supports the study of antidiabetic drugs that may reduce or slow down $\mathrm{AD}$ pathology.

Liraglutide (LRGT) is a glucagon-like peptide 1(GLP1) analog that has been widely assessed in animal models of AD. Initial studies with patients have shown modest beneficial effects and it is currently under evaluation in the ELAD trial (Evaluating Liraglutide in Alzheimer's Disease NCT01843075). We have reviewed available bibliography on the potential mechanisms through which LRGT may benefit AD. An overall improvement of brain metabolic alterations, amyloid $(A \beta)$ and tau 
pathologies, inflammation, and neuronal damage are observed in animal models, supporting further studies in patients.

\section{Main text \\ Preclinical studies}

Glucagon-like peptide 1 (GLP-1) is implicated in the control of glycemia and metabolic homeostasis, both in the periphery and the central nervous system $[7,8]$. Due to the importance of GLP-1 signaling on cognitive function [9] and the relationship between $\mathrm{AD}$ and T2D [10], GLP-1 analogs, and LRGT specifically, may provide a relevant venue to ameliorate AD pathology [11]. Previous studies have shown some controversial outcomes in AD models. Whereas brain weight $[12,13]$, hippocampal insulin [13-16], cortical glucose levels or brain GLUT1 and GLUT4 [13] do not seem to be affected, LRGT treatment increases GLP1-receptors in the hippocampus of AD mice [15-17]. Similarly, LRGT also increases insulin receptor levels in a primate model of AD [14], although no differences have been observed in AD mice [18]. LRGT ameliorates insulin resistance in the hippocampus by reducing phosphorylated insulin receptor levels $[19,20]$ and insulin receptor substrate-1 $[19,20]$. Interestingly, insulin degrading enzyme, that is reduced in $\mathrm{AD}$ preclinical models and a feasible underlying mechanism for $\mathrm{AD}$ and T2D [21, 22], is preserved or increased in the cortex and hippocampus from $\mathrm{AD}$ mice after LRGT treatment $[18,20]$.

Autopsy cohort studies have revealed a limited role of T2D on classical AD neuropathological features (amyloid $(A \beta)$ plaques and tau tangles) [4]. However, studies in animals show an overall improvement after different administration protocols $[12,13,23,24]$, including prophylactic [23] and long-term treatments [23, 25-27]. Whereas some studies have reported no effects on amyloid pathology [28], the majority of the results show that LRGT dramatically reduces $A \beta$ plaque size [29], number $[19,29]$, and burden $[18,23,30-32]$. LRGT also decreases $A \beta$ aggregates [30] and restores increased levels of $\beta$-secretase 1 and presenilin 1 [17] in the brain from an $\mathrm{AD}$ mice, once $\mathrm{A} \beta$ pathology is fully established (Fig. 1). Moreover, positive effects have also been observed when LRGT is administered before $A \beta$ plaques deposit [23]. In addition, LRGT limits tau hyperphosphorylation by modulating the activity of ERK and JNK in 3xTgAD [12, 13], APP/PS1 [29], and hTauP301L mice [33]. Likewise, LRGT reduces hippocampal tau phosphorylation by modulating Akt and GSK-3 $\beta$ [15], and in hyperhomocysteinemic rats, tau hyperphosphorylation is reduced through the activation of PP2Ac [17]. Likewise, LRGT neuroprotection is mediated by a reduction of neurofilament phosphorylation in 3xTgAD animals [12]. LRGT also improves synaptic plasticity [18, 34], density [14], structure [15, 27], and synapsis number [35], increasing synaptophysin and PSD-95 levels in AD mice [23, 30, 35 ] together with increased long-term potentiation and paired-pulse facilitation $[18,30,34,35]$. NMDA synapse-associated proteins are restored by LRGT in the hippocampus from hyperhomocysteinemic rats [17], and cAMP/PKA pathway is also improved [14, 34]. Additionally, LRGT not only attenuates neural loss and degeneration, but it also increases neurogenesis in the cortex $[18,23,26,35]$ and the subventricular zone $[31,32]$, reduces the number of degenerating cells in the cortex and hippocampus [12], and increases cell proliferation in the dentate gyrus of $\mathrm{AD}$ animals [26]. Inflammation is also a major feature in $\mathrm{AD}$ and previous studies show
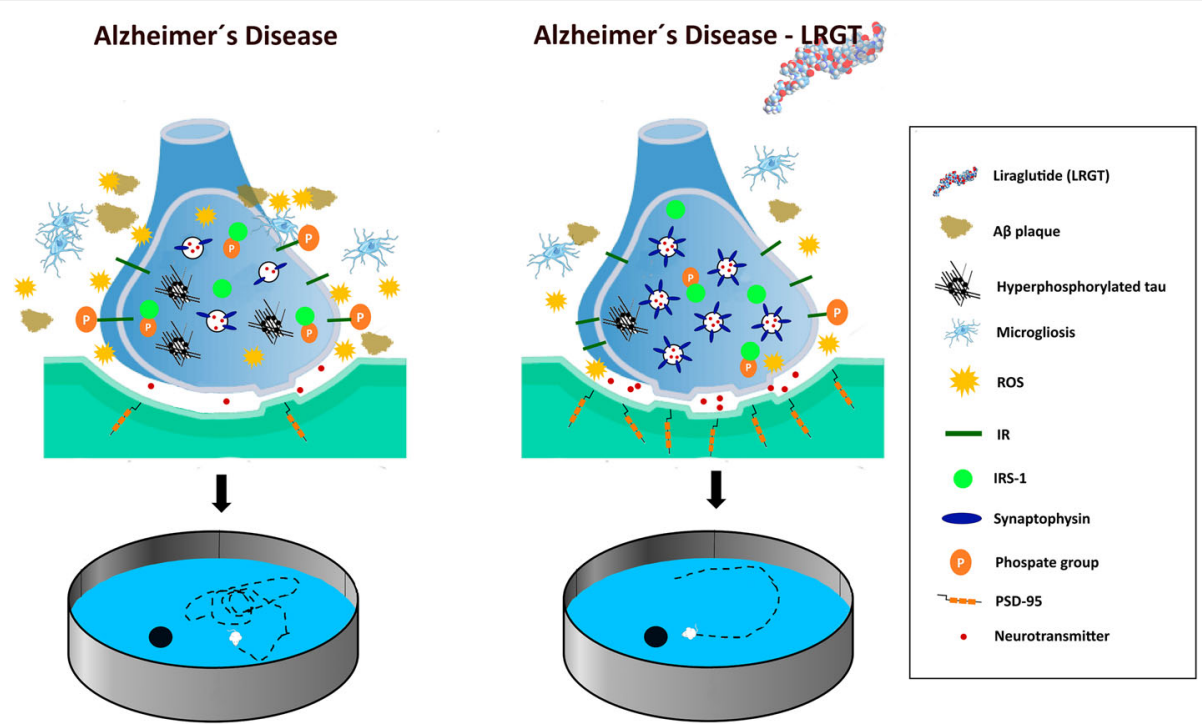

Fig. 1 Schematic effects of liraglutide in the brain with AD pathology 
that LRGT reduces microgliosis and astrocytosis in the cortex [19, 23, 30, 35] and hippocampus [29, 31, 32]. Besides, LRGT limits pro-inflammatory cytokines, including TNF- $\alpha$, IL-1ß, or IL-10 $[13,24]$. In line with these observations, LRGT also decreases brain oxidative stress, by reducing glucose-6-phosphate dehydrogenase activity, the formation of cortical carbonyl groups, nitrite and 8hydroxy-2'-deoxyguanosine in 3xTgAD mice [13]. Similarly, oxidative phosphorylation of cortical astrocytes is reduced in 5xFAD mice [27] (Fig. 1).

The positive effects of LRGT on AD-like pathology support the beneficial role of LRGT on learning and memory in most of the studies. In this sense, spatial working memory improves after LRGT treatment [12, $15,17,18,24]$, and LRGT also restores episodic memory in $\mathrm{AD}$ models $[14,18,23]$ (Fig. 1). In line with these observations, contextual fear conditioning [14], activeavoidance T-maze task [25], or clasping behavior [33] are also improved by LRGT, while locomotor activity does not seem affected $[12,17,23]$.

\section{Studies in AD patients}

The above described outcomes in preclinical models of AD have set the basis to futher assess LRGT in patients. Whereas other antidiabetic drugs, including GLP-1 analogs or dipeptidyl peptidase 4 inhibitors, have been part of preceding or ongoing clinical trials, studies with LRGT specifically are still limited. Previous metaanalysis has shown a pro-cognitive class effect of antidiabetic agents in $\mathrm{AD} /$ mild cognitive impairment, although the actual beneficial effects with LRGT are limited [36]. LRGT administration to individuals with subjective cognitive complaints, at risk for $\mathrm{AD}$, improves intrinsic connectivity within brain areas. While this did not translate into cognitive differences between study groups after 12 weeks of treatment [37], other studies have shown that treatment with LRGT to AD patients for 6 months raises blood-brain glucose transfer capacity, restoring glucose transport [38], as an initial requirement to improve brain alterations. Gejl et al. [39] (ClinicalTrials.gov NCT0146 9351) have also reported that treatment with LRGT to $\mathrm{AD}$ patients for 6 months prevents cerebral metabolic rate of glucose consumption decline, as an indicator of cognitive impairment, synaptic dysfunction, and disease evolution. Whereas $A \beta$ load or cognition do not seem to be affected, the authors state the study was underpowered. Another study with pre- or early diabetes patients has recently shown that LRGT improves short-term memory and memory composite in treated patients [40]. The ELAD trial is presently ongoing and the main objectives include evaluation of glucose metabolic consumption in cortical regions and cognition, MRI changes, microglial activation, and amyloid or tau changes [41], and the latest results will be published shortly.

\section{Conclusions}

Preclinical studies show beneficial effects of LRGT on AD pathological features and cognition. While the studies in patients have only shown moderate positive effects, the ongoing ELAD trial may provide relevant insights on the actual role of LRGT at central level and open new venues of treatment for AD patients.

\section{Abbreviations \\ Aß: Amyloid- $\beta$; AD: Alzheimer's disease; T2D: Type 2 diabetes; GLP- 1: Glucagon-like peptide 1; LRGT: Liraglutide}

\section{Acknowledgements}

Not applicable

\section{Authors' contributions}

MVS and MJCN drafted the manuscript. ADM and MGA drafted parts of the manuscript and revised and completed the manuscript. The authors read and approved the final manuscript.

\section{Funding}

MG-A: Programa Estatal de I+D+l orientada a los Retos de la Sociedad (BFU 2016-75038-R), financed by the Agencia Estatal de Investigación (AEI) and the Fondo Europeo de Desarrollo Regional (FEDER), Ministerio de Ciencia, Innovación y Universidades. Explora Ciencia. Ministerio de Ciencia, Innovación y Universidades (BFU2017-91910-EXP). Subvención para la financiación de la investigación y la innovación biomédica y en ciencias de la salud en el marco de la iniciativa territorial integrada 2014-2020 para la provincia de Cádiz. Consejeria de Salud. Junta de Andalucía. Unión Europea, financed by the Fondo de Desarrollo Regional (FEDER) (PI-0008-2017).

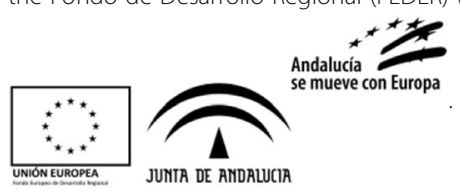

Availability of data and materials Not applicable.

\section{Declarations}

Ethics approval and consent to participate Not applicable.

\section{Consent for publication}

Not applicable.

\section{Competing interests}

The authors declare that they have no competing interests.

\section{Author details}

${ }^{1}$ Division of Physiology, School of Medicine, Instituto de Investigacion Biomedica de Cadiz (INIBICA), Universidad de Cadiz, Edificio Andres Segovia, C/Dr. Maranon 3, 3er piso, Cadiz, Spain. ${ }^{2}$ Salus Infirmorum-Universidad de Cadiz, Cadiz, Spain.

Received: 21 May 2021 Accepted: 31 May 2021

Published online: 12 June 2021

\section{References}

1. Sims-Robinson C, Kim B, Rosko A, Feldman EL. How does diabetes accelerate Alzheimer disease pathology? Nat Rev Neurol. 2010;6(10):551-9. https://doi.org/10.1038/nrneurol.2010.130.

2. Ryu JC, Zimmer ER, Rosa-Neto P, Yoon SO. Consequences of metabolic disruption in Alzheimer's disease pathology. Neurotherapeutics. 2019;16(3): 600-10. https://doi.org/10.1007/s13311-019-00755-y.

3. Arnold SE, Arvanitakis Z, Macauley-Rambach SL, Koenig AM, Wang HY, Ahima RS, et al. Brain insulin resistance in type 2 diabetes and Alzheimer 
disease: concepts and conundrums. Nat Rev Neurol. 2018;14(3):168-81. https://doi.org/10.1038/nrneurol.2017.185.

4. Biessels GJ, Despa F. Cognitive decline and dementia in diabetes mellitus: mechanisms and clinical implications. Nat Rev Endocrinol. 2018;14(10):591604. https://doi.org/10.1038/s41574-018-0048-7.

5. Wang KC, Woung LC, Tsai MT, Liu CC, Su YH, Li CY. Risk of Alzheimer's disease in relation to diabetes: a population-based cohort study. Neuroepidemiology. 2012;38(4):237-44. https://doi.org/10.1159/000337428.

6. Huang CC, Chung CM, Leu HB, Lin LY, Chiu CC, Hsu CY, et al. Diabetes mellitus and the risk of Alzheimer's disease: a nationwide population-based study. PLoS One. 2014;9(1):e87095. https://doi.org/10.1371/journal.pone. 0087095.

7. Timper K, Del Rio-Martin A, Cremer AL, Bremser S, Alber J, Giavalisco P, et al. GLP-1 Receptor signaling in astrocytes regulates fatty acid oxidation, mitochondrial integrity, and function. Cell Metab. 2020;31(6):1189-205 e13. https://doi.org/10.1016/j.cmet.2020.05.001.

8. Katsurada K, Yada T. Neural effects of gut- and brain-derived glucagon-like peptide-1 and its receptor agonist. J Diabetes Investig. 2016;7(Suppl 1):64-9. https://doi.org/10.1111/jdi.12464.

9. Grieco M, Giorgi A, Gentile MC, d'Erme M, Morano S, Maras B, et al. Glucagon-like peptide-1: a focus on neurodegenerative diseases. Front Neurosci. 2019;13:1112. https://doi.org/10.3389/fnins.2019.01112.

10. Chatterjee S, Mudher A. Alzheimer's disease and type 2 diabetes: a critical assessment of the shared pathological traits. Front Neurosci. 2018;12:383. https://doi.org/10.3389/fnins.2018.00383.

11. Wicinski M, Socha M, Malinowski B, Wodkiewicz E, Walczak M, Gorski K, et al. Liraglutide and its neuroprotective properties-focus on possible biochemical mechanisms in alzheimer's disease and cerebral ischemic events. Int J Mol Sci. 2019;20(5).

12. Chen S, Sun J, Zhao G, Guo A, Chen Y, Fu R, et al. Liraglutide improves water maze learning and memory performance while reduces hyperphosphorylation of tau and neurofilaments in APP/PS1/Tau triple transgenic mice. Neurochem Res. 2017;42(8):2326-35. https://doi.org/10.1 007/s11064-017-2250-8.

13. Duarte Al, Candeias E, Alves IN, Mena D, Silva DF, Machado NJ, et al. Liraglutide protects against brain amyloid-beta1-42 accumulation in female mice with early Alzheimer's disease-like pathology by partially rescuing oxidative/nitrosative stress and inflammation. Int J Mol Sci. 2020;21 (5).

14. Batista AF, Forny-Germano L, Clarke JR, Lyra ESNM, Brito-Moreira J, Boehnke $\mathrm{SE}$, et al. The diabetes drug liraglutide reverses cognitive impairment in mice and attenuates insulin receptor and synaptic pathology in a nonhuman primate model of Alzheimer's disease. J Pathol. 2018;245(1):85-100. https://doi.org/10.1002/path.5056.

15. Qi L, Ke L, Liu X, Liao L, Ke S, Liu X, et al. Subcutaneous administration of liraglutide ameliorates learning and memory impairment by modulating tau hyperphosphorylation via the glycogen synthase kinase-3beta pathway in an amyloid beta protein induced Alzheimer disease mouse model. Eur J Pharmacol. 2016;783:23-32. https://doi.org/10.1016/j.ejphar.2016.04.052.

16. Qi L, Chen Z, Wang Y, Liu X, Liu X, Ke L, et al. Subcutaneous liraglutide ameliorates methylglyoxal-induced Alzheimer-like tau pathology and cognitive impairment by modulating tau hyperphosphorylation and glycogen synthase kinase-3beta. Am J Transl Res. 2017;9(2):247-60.

17. Zhang Y, Xie JZ, Xu XY, Hu J, Xu T, Jin S, et al. Liraglutide ameliorates hyperhomocysteinemia-induced Alzheimer-like pathology and memory deficits in rats via multi-molecular targeting. Neurosci Bull. 2019;35(4):72434. https://doi.org/10.1007/s12264-018-00336-7.

18. McClean PL, Holscher C. Liraglutide can reverse memory impairment, synaptic loss and reduce plaque load in aged APP/PS1 mice, a model of Alzheimer's disease. Neuropharmacology. 2014;76(Pt A):57-67.

19. Long-Smith CM, Manning S, McClean PL, Coakley MF, O'Halloran DJ, Holscher C, et al. The diabetes drug liraglutide ameliorates aberrant insulin receptor localisation and signalling in parallel with decreasing both amyloid-beta plaque and glial pathology in a mouse model of Alzheimer's disease. NeuroMolecular Med. 2013;15(1):102-14. https://doi.org/10.1007/s12 017-012-8199-5.

20. Paladugu L, Gharaibeh A, Kolli N, Learman C, Hall TC, Li L, et al. Liraglutide has anti-inflammatory and anti-amyloid properties in streptozotocininduced and 5XFAD mouse models of Alzheimer's disease. Int J Mol Sci. 2021;22(2).

21. Kulas JA, Franklin WF, Smith NA, Manocha GD, Puig KL, Nagamoto-Combs K, et al. Ablation of amyloid precursor protein increases insulin-degrading enzyme levels and activity in brain and peripheral tissues. Am J Physiol Endocrinol Metab. 2019;316(1):E106-E20. https://doi.org/10.1152/ajpendo. 00279.2018.

22. Li H, Wu J, Zhu L, Sha L, Yang S, Wei J, et al. Insulin degrading enzyme contributes to the pathology in a mixed model of type 2 diabetes and Alzheimer's disease: possible mechanisms of IDE in T2D and AD. Biosci Rep. 2018;38(1).

23. McClean PL, Jalewa J, Holscher C. Prophylactic liraglutide treatment prevents amyloid plaque deposition, chronic inflammation and memory impairment in APP/PS1 mice. Behav Brain Res. 2015;293:96-106. https://doi. org/10.1016/j.bbr.2015.07.024.

24. Maskery M, Goulding EM, Gengler S, Melchiorsen JU, Rosenkilde MM, Holscher C. The dual GLP-1/GIP receptor agonist DA4-JC shows superior protective properties compared to the GLP-1 analogue liraglutide in the APP/PS1 mouse model of Alzheimer's disease. Am J Alzheimers Dis Other Dement. 2020;35:1533317520953041.

25. Hansen HH, Fabricius K, Barkholt P, Niehoff ML, Morley JE, Jelsing J, et al. The GLP-1 receptor agonist liraglutide improves memory function and increases hippocampal CA1 neuronal numbers in a senescence-accelerated mouse model of Alzheimer's disease. J Alzheimers Dis. 2015;46(4):877-88. https://doi.org/10.3233/JAD-143090.

26. Parthsarathy V, Holscher C. Chronic treatment with the GLP1 analogue liraglutide increases cell proliferation and differentiation into neurons in an AD mouse model. PLoS One. 2013;8(3):e58784. https://doi.org/10.1371/ journal.pone.0058784.

27. Zheng J, Xie Y, Ren L, Qi L, Wu L, Pan X, et al. GLP-1 improves the supportive ability of astrocytes to neurons by promoting aerobic glycolysis in Alzheimer's disease. Mol Metab. 2021;47:101180. https://doi.org/10.1016/j. molmet.2021.101180.

28. Hansen HH, Fabricius K, Barkholt P, Kongsbak-Wismann P, Schlumberger C, Jelsing J, et al. Long-term treatment with liraglutide, a glucagon-like peptide-1 (GLP-1) receptor agonist, has no effect on beta-amyloid plaque load in two transgenic APP/PS1 mouse models of Alzheimer's disease. PLoS One. 2016;11(7):e0158205. https://doi.org/10.1371/journal.pone.0158205.

29. Holubova M, Hruba L, Popelova A, Bencze M, Prazienkova V, Gengler S, et al. Liraglutide and a lipidized analog of prolactin-releasing peptide show neuroprotective effects in a mouse model of beta-amyloid pathology. Neuropharmacology. 2019;144:377-87. https://doi.org/10.1016/j.neuropha rm.2018.11.002.

30. McClean PL, Parthsarathy V, Faivre E, Holscher C. The diabetes drug liraglutide prevents degenerative processes in a mouse model of Alzheimer's disease. J Neurosci. 2011;31(17):6587-94. https://doi.org/10.1523/ JNEUROSCI.0529-11.2011.

31. Salles GN, Calio ML, Holscher C, Pacheco-Soares C, Porcionatto M, Lobo AO. Neuroprotective and restorative properties of the GLP-1/GIP dual agonist DA-JC1 compared with a GLP-1 single agonist in Alzheimer's disease. Neuropharmacology. 2020;162:107813. https://doi.org/10.1016/j.neuropha rm.2019.107813.

32. Salles GN, Calio ML, Afewerki S, Pacheco-Soares C, Porcionatto M, Holscher $C$, et al. Prolonged drug-releasing fibers attenuate Alzheimer's disease-like pathogenesis. ACS Appl Mater Interfaces. 2018;10(43):36693-702. https://doi. org/10.1021/acsami.8b12649.

33. Hansen HH, Barkholt P, Fabricius $K$, Jelsing J, Terwel D, Pyke C, et al. The GLP-1 receptor agonist liraglutide reduces pathology-specific tau phosphorylation and improves motor function in a transgenic hTauP301L mouse model of tauopathy. Brain Res. 2016;1634:158-70.

34. Han WN, Holscher C, Yuan L, Yang W, Wang XH, Wu MN, et al. Liraglutide protects against amyloid-beta protein-induced impairment of spatial learning and memory in rats. Neurobiol Aging. 2013;34(2):576-88. https:// doi.org/10.1016/j.neurobiolaging.2012.04.009.

35. McClean PL, Holscher C. Lixisenatide, a drug developed to treat type 2 diabetes, shows neuroprotective effects in a mouse model of Alzheimer's disease. Neuropharmacology. 2014;86:241-58. https://doi.org/10.1016/j. neuropharm.2014.07.015.

36. Cao B, Rosenblat JD, Brietzke E, Park C, Lee Y, Musial N, et al. Comparative efficacy and acceptability of antidiabetic agents for Alzheimer's disease and mild cognitive impairment: a systematic review and network meta-analysis. Diabetes Obes Metab. 2018;20(10):2467-71. https://doi.org/10.1111/dom.133 73.

37. Watson KT, Wroolie TE, Tong G, Foland-Ross LC, Frangou S, Singh M, et al. Neural correlates of liraglutide effects in persons at risk for Alzheimer's 
disease. Behav Brain Res. 2019;356:271-8. https://doi.org/10.1016/j.bbr.2018. 08.006 .

38. Gejl M, Brock B, Egefjord L, Vang K, Rungby J, Gjedde A. Blood-brain glucose transfer in Alzheimer's disease: effect of GLP-1 analog treatment. Sci Rep. 2017;7(1):17490. https://doi.org/10.1038/s41598-017-17718-y.

39. Gejl M, Gjedde A, Egefjord L, Moller A, Hansen SB, Vang K, et al. In Alzheimer's disease, 6-month treatment with GLP-1 analog prevents decline of brain glucose metabolism: randomized, placebo-controlled, double-blind clinical trial. Front Aging Neurosci. 2016;8:108.

40. Vadini F, Simeone PG, Boccatonda A, Guagnano MT, Liani R, Tripaldi $R$, et al. Liraglutide improves memory in obese patients with prediabetes or early type 2 diabetes: a randomized, controlled study. Int J Obes. 2020;44(6): 1254-63. https://doi.org/10.1038/s41366-020-0535-5.

41. Femminella GD, Frangou E, Love SB, Busza G, Holmes C, Ritchie C, et al. Evaluating the effects of the novel GLP-1 analogue liraglutide in Alzheimer's disease: study protocol for a randomised controlled trial (ELAD study). Trials. 2019;20(1):191. https://doi.org/10.1186/s13063-019-3259-x.

\section{Publisher's Note}

Springer Nature remains neutral with regard to jurisdictional claims in published maps and institutional affiliations.

Ready to submit your research? Choose BMC and benefit from:

- fast, convenient online submission

- thorough peer review by experienced researchers in your field

- rapid publication on acceptance

- support for research data, including large and complex data types

- gold Open Access which fosters wider collaboration and increased citations

- maximum visibility for your research: over $100 \mathrm{M}$ website views per year

At $\mathrm{BMC}$, research is always in progress.

Learn more biomedcentral.com/submissions 